'llu. Revista de Ciencias de las Religiones

ISSN: $1135-4712$

https://dx.doi.org/10.5209/ilur.75199

\title{
La amidá en la liturgia rabínica: ¿creación o adaptación?
}

\author{
Javier del Barco del Barco
}

Recibido: 7 de febrero de 2019 / Aceptado: 3 de junio de 2019

Resumen. En este artículo se trata sobre la controvertida cuestión del origen de la amidá, principal oración del servicio religioso judío, en el contexto de creación de la liturgia rabínica tras la destrucción del Templo de Jerusalén en el año 70 d. C. Para ello se analiza primero su estructura formal y literaria, ofreciendo a continuación un análisis crítico sobre su origen que se hace eco del debate académico acerca de la cuestión. En apéndice se ofrece una traducción anotada de esta oración rabínica del s. I d. C. Palabras clave: Amidá; liturgia; judaísmo; rabínico; origen; estructura; traducción.

\section{[en] The Amidah in Rabbinic Liturgy: Creation or Adaptation?}

\begin{abstract}
This article discusses one of the most controversial topics on the creation of Rabbinic Jewish Liturgy - the origin of the Amidah, the main prayer in the Jewish religious public service, after the destruction of the Second Temple in 70 C. E. To this end, the formal and literary structure of the Amidah is analyzed followed by a critical discussion on its origin that contributes to the scholarly debate on the topic. An annotated Spanish translation of this first-century prayer is rendered as an Appendix.
\end{abstract}

Keywords: Amidah; Liturgy; Judaism; Rabbinic; Origen; Structure; Translation.

Sumario. 1. Introducción. 2. Estructura formal. 3. Estructura literaria. 4. Origen y desarrollo. 5. Apéndice: Una traducción anotada de la amidá. 6. Bibliografía.

Cómo citar: Del Barco, J. (2021), La amidá en la liturgia rabínica: ¿creación o adaptación?, en 'Ilu. Revista de Ciencias de las Religiones 24, 21-39.

\section{Introducción}

La amidá es la principal oración del servicio religioso judío en la sinagoga ${ }^{2}$. Es su punto central y no hay servicio religioso en el que no se recite esta oración en alguna

1 Instituto de Lenguas y Culturas del Mediterráneo y Oriente Próximo, CSIC.

Correo electrónico: javier.delbarco@csic.es

ORCID iD: https://orcid.org/0000-0002-7932-6710

2 El servicio religioso de los días de diario se celebra tres veces al día: por la mañana (matutino o šaharit), por la tarde (vespertino o minhah) y por la noche (nocturno, arbit o ma 'arib). El vespertino se celebra a última hora de la tarde y el nocturno a primera hora de la noche, para que los dos puedan celebrarse seguidos. El sábado y las fiestas se celebra además un servicio adicional (musaf) inmediatamente después del servicio matutino. El Día de la Expiación (yom kippur), además de los tres servicios regulares y del adicional, se celebra un quinto 
de sus formas ${ }^{3}$. Es una oración básicamente peticionaria, que incluye también elementos de alabanza y de acción de gracias. Su lenguaje es el característico de la época rabínica temprana (período tanaítico), aunque contiene no pocas expresiones de cuño bíblico. Constituye, además, la oración más importante en la articulación de la liturgia rabínica, entendida esta como el conjunto de oraciones obligatorias establecidas al inicio del período rabínico clásico (después de la destrucción del Templo en el año $70 \mathrm{~d}$. C.) para sustituir el culto en el Templo y otras liturgias asociadas a éste.

Según la tradición rabínica, R. Gamaliel II ordenó en la asamblea de rabinos celebrada en Yavne a finales del s. I d. C. la redacción de la amidá a Simeón haPaquli, en forma de dieciocho bendiciones, y estableció la obligatoriedad de su recitación tres veces al día para todo Israel ${ }^{4}$. La tradición rabínica parece incidir en que se utilizaron materiales anteriores muy antiguos, por lo que tradicionalmente se ha aceptado la idea de que en Yavne se editó el texto dando forma definitiva a las bendiciones que se incluyeron, que serían en su mayoría preexistentes, y decidiendo asimismo el orden en que habían de ser recitadas. No obstante, también se ha considerado la idea de que la amidá pudo haber sido creada ex nihilo, es decir, sin atender a la existencia de elementos litúrgicos orales anteriores a la destrucción del Templo de Jerusalén en el año 70 d. C. Este debate sobre el origen de la amidá constituye, precisamente, uno de los temas más discutidos en el ámbito del estudio de la liturgia judía en general, y de la liturgia en época rabínica en particular.

Este artículo pretende precisamente ofrecer el estado sobre esta cuestión, recogiendo las aportaciones más recientes sobre el tema para ofrecer un análisis crítico y argumentado, que no pretende ni puede ser definitivo. Previo a ello, se ofrece un estudio de la estructura formal y estructura literaria de la amidá tal y como se recita hoy en día ${ }^{5}$. Ambos elementos son clave para las consideraciones sobre su posible

servicio llamado ne 'ilat še 'arim ('cierre de las puertas'), o simplemente ne 'ila, en recuerdo del momento en que se cerraban las puertas del Templo de Jerusalén y de la liturgia no sacrificial que se celebraba en esa ocasión.

3 Esto no siempre fue así: en el servicio nocturno la amidá fue en principio opcional, como reflejan la Misná y el Talmud (vid. mBer. 4:1; bBer. 27b; yBer. 4:1-2, 7d). Es probable que la introducción de la amidá en el servicio nocturno pueda deberse a una equiparación con los servicios matutino y vespertino, en los que es obligatoria; Elbogen $(1993,85)$, sugiere que puede haber una influencia de la liturgia que se celebraba en el Templo en el momento del cierre de las puertas y que tiene reflejo en el servicio especial de ne ilah que se celebra en la actualidad únicamente en el Día de la Expiación. Sin embargo, esta suposición parece poco probable. Hay que recordar que los servicios matutino y vespertino se corresponden, según la tradición rabínica, con los sacrificios de la mañana y de la tarde (llamados tamid) que se celebraban a diario en el Templo y que constituían el elemento central de la liturgia cúltica que existía antes de la destrucción del año 70. En este sentido, la recitación de la amidá sería un sacrificio espiritual sustituto del sacrificio real que se realizaba antes del año 70. En el servicio nocturno, debido a que éste no se corresponde con ningún sacrificio que se realizara en el Templo, la amidá no era obligatoria, y parece lógico pensar que sólo con el paso del tiempo se institucionalizó su recitación obligatoria para equiparar la liturgia del servicio nocturno con la de los servicios matutino y vespertino.

$4 \quad$ bMeg. 17b-18a; bBer. 28b. Otra tradición atribuye la instauración de la amidá a la Gran Asamblea, institución mítica de la época del Segundo Templo mencionada en las fuentes rabínicas. Tal atribución parece ser un típico elemento justificativo que busca autoridad con el argumento de la antigüedad en un pasado mítico.

5 Se ha optado por ofrecer una traducción del texto que se encuentra hoy en día en los siddurim, y no el de alguna de las recensiones antiguas (palestinense o babilónica), o el hallado en la Genizah de El Cairo (Schechter 1898), por varias razones. Una, porque el texto de las recensiones no se corresponde necesariamente con la supuesta versión más antigua. Dos, porque hasta su definitiva fijación el texto de la amidá era bastante flexible y sin una única formulación (vid. Stemberger 2011 [2009], 100). Y tres, porque aquí no se pretende hacer un estudio crítico sobre el texto de la amidá, sino ofrecer un estado de la cuestión sobre el origen de la oración, así como comprender la estructura y significado de la versión que ha llegado a nosotros en la liturgia judía. 
origen. Finalmente, como apéndice, se incluye, por primera vez en el panorama académico español, una traducción anotada realizada directamente desde el hebreo de esta oración fundamental del servicio litúrgico judío 6 .

\section{Estructura formal}

La amidá es una oración compuesta por una serie de bendiciones (berakot). En esto se distingue de otras oraciones constituyentes de la liturgia judía, y muy especialmente del šema', puesto que la parte fundamental de esta última está compuesta de versículos bíblicos ${ }^{7}$, tomados de los libros de Números y Deuteronomio ${ }^{8}$.

La bendición es una forma de oración fundamental en el acto religioso de comunicación entre el creyente y la divinidad. Tal acto de comunicación puede dividirse en tres categorías: oración de alabanza, oración peticionaria, y acción de gracias. La amidá, si bien constituye fundamentalmente una oración peticionaria, contiene bendiciones que pueden adscribirse a las tres categorías antes mencionadas. De las diecinueve bendiciones en que consiste, las tres primeras son consideradas bendiciones de alabanza; las trece siguientes, que constituyen la sección intermedia, son peticiones, tanto comunales como personales, y las tres últimas son bendiciones de acción de gracias. Tal estructura es, sin embargo, discutida por algunos especialistas, como veremos más adelante al tratar de la estructura literaria de la oración.

Cada bendición presenta una estructura articulada en dos partes: una primera parte en la que se describe el motivo de alabanza, de acción de gracias, o la petición, y una segunda parte que contiene la expresión de la bendición a la divinidad, o eulogía, que constituye el elemento nuclear de cada bendición. De las distintas fórmulas existentes para expresar la eulogía, la que se eligió como más apropiada en la amidá es Baruk attah Yahve, 'Bendito seas, Yahvé' . Tras ese elemento invocativo, se desarrolla el atributo o la acción divinas que han sido motivo de tratamiento en la primera parte de la bendición.

El nombre de la oración se refiere a la postura, de pie, en que los congregantes se encuentran mientras dura su recitación. Este nombre es el más común en la tradición sefardí, y el que se utiliza normalmente en los estudios académicos que tratan de la amidá. En la literatura rabínica se la conoce simplemente como ha-tefil·lah ('la oración'), aunque ese nombre cayó en desuso debido a que designa también el término genérico. La tradición askenazí utiliza el nombre de šemone eśre ('dieciocho'), pues-

6 Existe una traducción anterior al español de las recensiones palestinense y babilónica en Schürer (1985 [1979], 2:590-599). No obstante, estas traducciones están hechas a partir del original en inglés de la obra de Schürer, y no a partir del hebreo.

7 El uso de secciones de la Biblia en la liturgia judía es enormemente amplio y muy interesante a la hora de estudiar los contextos en los que se insertan estas secciones y los nuevos significados que adquieren, especialmente desde un punto de vista literario y religioso; vid. p. ej. Reif 2006, 71-92; Langer 2007; Naeh 2006; y Brody 2006.

8 De 6,4, de donde toma su nombre; De 6,5-9; 11, 13-21; Núm 15,37-41. No obstante, en la liturgia sinagogal esta oración también está precedida y seguida de varias bendiciones, y forma, en opinión de algunos, una unidad litúrgica junto con la amidá; en este sentido, vid. Kimelman 1997a, 117.

9 Esta eulogía recibe el nombre de mațbea 'qașar ('[bendición] de cuño corto’), frente a la más larga «Bendito seas, Yahvé nuestro Dios, rey del mundo», que recibe el nombre de matbea 'arok ('[bendición] de cuño largo'); se prefirió la primera a otras fórmulas bíblicas de bendición preexistentes, como hal·lelu-yah, 'alabad al Señor'. 
to que según las fuentes rabínicas la oración se instituyó con ese número de bendiciones, que después serían diecinueve ${ }^{10}$. Este nombre es el más popular entre los judíos procedentes de Europa en la actualidad.

En la liturgia sinagogal, la amidá se recita, generalmente, repetida ${ }^{11}$ : a la recitación silenciosa (o en voz baja) que realiza cada uno de manera personal, le sigue la repetición que efectúa el oficiante en voz alta, y que incluye algunos añadidos y variantes con respecto al texto recitado primeramente ${ }^{12}$. Dos son los añadidos fundamentales que se incluyen en la oración cuando el oficiante la repite: el primero es la llamada qedušah ('santificación'), y consiste en una selección de versículos bíbli$\cos ^{13}$ (Isa 6,3; Ez 3,12; Sal 146,10), unidos por algunas frases de transición, que ensalzan la santidad de Dios sobre todas las cosas, así como la eternidad de su reino ${ }^{14}$. Está en relación con la bendición III (sobre la santidad de Dios) y es recitada antes de esta en la repetición que efectúa el oficiante. El segundo añadido es la llamada bendición sacerdotal (birkat kohanim). Esta bendición consiste en la recitación de Núm 6,24-26 antes de la bendición XIX, y tiene su origen en la liturgia cúltica del Templo de Jerusalén, en la que los sacerdotes la pronunciaban antes de realizar cada uno de los sacrificios diarios en las escalinatas del pórtico del Templo para bendecir a los allí congregados. La inserción de esta bendición, que claramente rompe el hilo conductor de la amidá, ha sido explicada como un resto de la que en época del segundo Templo se efectuaba en las sinagogas durante las sesiones de estudio, tomada a su vez de la que se recitaba en el Templo, especialmente en la liturgia de las ma 'amadot ${ }^{15}$; una vez modificada la función de la sinagoga y convertida en lugar de liturgia comunal, se siguió la costumbre de pedir a los kohanim que bendijeran a los congregantes, sobre todo cuando ya no había Templo ni sacerdotes que realizaran los sacrificios diarios ${ }^{16}$.

El número de dieciocho bendiciones (diecinueve en la actualidad) es el que se institucionalizó para la amidá de los días ordinarios no festivos. El mantenimiento

10 La bendición XII, sobre los apóstatas, fue incluida, en opinión de algunos, poco tiempo después de institucionalizarse la amidá; vid. Elbogen 1993, 31-33 [27-29]. Otros, como Langer (2003, 141), opinan que no es posterior. Se incluyera o no poco después, parece que el número de dieciocho bendiciones, con algún significado simbólico, se siguió manteniendo en Palestina. Para ello, había cierta libertad a la hora de unir dos bendiciones en una, o separar una en dos, según los temas tratados. En Babilonia, las bendiciones XIV y XV, sobre Jerusalén y David, se convirtieron en dos bendiciones separadas, cuando temáticamente constituyen una sola unidad: el tema de la restauración del trono de David está ya introducido en la bendición sobre Jerusalén. La versión con diecinueve bendiciones sancionada en Babilonia es la que se convertiría en oficial en la liturgia posterior. Vid. Langer 2003, 132-135; y Heinemann 1977, 221-224.

11 En los servicios matutino, vespertino, y adicional. No así en el servicio nocturno, donde antiguamente era opcional.

12 La repetición de la amidá se institucionalizó para que aquellos que no la conocieran de memoria pudieran participar de su recitación diciendo amén al final de cada bendición junto con el resto de la congregación.

13 Vid. tBer. I, 9.

14 La qedušah va precedida de una pequeña introducción que es distinta en los ritos sefardí y hasídico, por una parte, y askenazí, por otra. Una variante de la qedušah (constituida por Isa 6,3 y Ez 3,12) es recitada por la congregación en la primera bendición (llamada yoșer) que precede al šema'; esta variante recibe el nombre de qedušah de-yoṣer. Es difícil saber cuál de ambas versiones empezó a utilizarse primero, pero puede asegurarse que en el período amoraítico, la qedušah de la amidá ya se recitaba en Palestina y, por tanto, es probable que también para entonces se recitara la qedušah de-yoṣer en el šema '; vid. Heinemann 1977, 230-231; también vid. Elbogen 1993, 54-57 [47-50], y en particular 59-61 para la discusión de Scheindlin sobre el origen y la relación de ambas versiones.

15 Sobre la liturgia de las ma 'amadot, vid. Tabory 2003, 115-117; Elbogen 1993, 187-195 [177-185].

16 Vid. Fleischer 1993, 208-210; Elbogen 1993, 62-66 [54-57]. 
de ese número en época temprana, por lo menos en Palestina, aun cuando los límites entre las bendiciones no parecían del todo establecidos, e incluso después de incluirse la bendición sobre los apóstatas, parece responder a una intención que daría a ese número precisamente un significado simbólico cuasi mágico ${ }^{17}$. No obstante, en la liturgia del sábado, en el servicio adicional de las fiestas, y en los tres festivales de peregrinación (šaloš regalim: Pascua, Pentecostés y Tabernáculos), la amidá no contiene diecinueve sino siete bendiciones. La de siete bendiciones (birkat ha-šeba ) presenta una estructura en la que las tres primeras y las tres últimas bendiciones son idénticas a las de la amidá de los días ordinarios, mientras que la sección intermedia está compuesta, en el caso de la amidá de siete bendiciones, por una única sección con referencias a la especificidad de la fiesta que se celebra. Por otro lado, en la fiesta de Año Nuevo (roš ha-šanah), la amidá contiene nueve bendiciones; en este caso, la sección intermedia está compuesta por una bendición similar a la de los días de fiesta además de otras tres que ensalzan a Dios como rey, juez y redentor; la primera de ellas, la que se refiere a Dios como rey, se incorpora como prolongación de la anterior, por lo que el total de bendiciones queda en nueve.

Es común que se explique la diferencia en el número de bendiciones de la sección intermedia como una sustitución de las trece bendiciones peticionarias de los días ordinarios por una bendición (o tres en el caso de Año Nuevo) no peticionaria que hace referencia a la santificación del sábado o a la especificidad de la fiesta que se celebra ${ }^{18}$. Si bien esto es cierto en la práctica litúrgica, no parece que el origen de la amidá del sábado y de los días de fiesta se haya producido por el método de la sustitución de las trece bendiciones intermedias por las específicas de esos días. Dicho de otro modo, en opinión de algunos, la amidá de siete bendiciones podría ser anterior incluso a la institucionalización de la amidá de los días ordinarios, con dieciocho bendiciones ${ }^{19}$.

17 Kahana $(2007,39)$ defiende la teoría de la ordenación de los tratados de la Misná atendiendo a cuestiones numerológicas, y la pone en relación con el número de bendiciones, dieciocho, de la amidá; según esta teoría, los números 3 y 7 y sus múltiplos tendrían significados simbólicos determinados, de manera que, prestando atención al número de capítulos de cada tratado, la estructura de la Misná, según el orden de R. Tanhuma, sería quiástico: $7+11+12(=30)+12+11+7(=30)$, resultando 30 capítulos en cada mitad (múltiplo de 3$)$ y existiendo 6 órdenes en la Misná con un total de 60 tratados (también múltiplos de 3). En este sentido, la estructura de la amidá estaría basada de igual modo en 3 y múltiplos de 3 , en una estructura también quiástica: $3+6$ $+6+3$ (=18 bendiciones). Cfr. la estructura $1+5+5+1$ de la sección intermedia de la amidá que propone Fleischer $(1993,198)$.

18 Así p. ej. Elbogen 1993, 93 [84]: «The 'Amida of the Sabbath differs from that of weekdays in that the thirteen middle benedictions drop up and are replaced by a single benediction»; más recientemente, Langer 2003, 128 : «The intermediate benedictions on weekdays are petitionary; these are replaced by a single blessing acknowledging the sacred nature of the day on Sabbaths and festivals».

19 Vid. Heinemann 1977, 226s.: «The custom of reciting only seven benedictions on Shabbats and festivals (instead of eighteen benedictions) is not to be explained as a result of the "deletion" of the intermediary (petitionary) benedictions on these days. [...] The Seven Benedictions for Shabbats and festivals, then, would not seem to be an "abbreviation" of the weekday Eighteen Benedictions, but rather, another traditional "series of prayers" which, apparently, was customarily recited on Shabbats and festivals even before the Eighteen Benedictions for weekdays had become an established custom». Sobre la bendición intermedia de la amidá del sábado, vid. Fleischer 1995; Weinfeld 2005, 137-156. Heinemann (1977, 228s.) defiende la existencia de series de bendiciones en distintas formas y estilos que antecederían al establecimiento de la amidá de dieciocho bendiciones: además de la amidá de siete bendiciones, menciona también el caso de la serie de bendiciones que se recitan tras la lectura de la sección de profetas (haftarah), y la serie que recitaba el sumo sacerdote tras la lectura del Pentateuco en el Día de la Expiación (yom kippur). 


\section{Estructura literaria}

Es tradicional desde la época rabínica dividir la amidá en tres partes, cada una de las cuales con bendiciones de un tipo determinado. Según esta división, la primera parte es una introducción de alabanza a Dios, la última parte una conclusión de acción de gracias, y la sección intermedia constituye una oración peticionaria ${ }^{20}$. La primera parte está constituida por las primeras tres bendiciones, consideradas como de alabanza a Dios. Estas bendiciones ensalzan a Dios como protector de los antepasados (I), Dios todopoderoso (II), y Dios santo (III). La última parte comprende las tres últimas bendiciones, que conforman una sección final de acción de gracias, si bien sólo la bendición XVIII es realmente una oración de acción de gracias («Te damos gracias por ser Tú Yahvé nuestro Dios y el Dios de nuestros padres, eternamente»). Las otras dos piden a Dios la aceptación de la oración y la reinstauración del culto en el Templo (XVII), así como la paz y la bendición de Dios sobre todo Israel (XIX). La sección intermedia está compuesta por bendiciones peticionarias de distinto tipo, que tradicionalmente se suelen denominar peticiones personales y peticiones de toda la comunidad de Israel ${ }^{21}$.

Esta estructura literaria tradicional ha sido puesta en duda por algunos especialistas debido a los problemas que un análisis pormenorizado del texto suscita ${ }^{22}$. Como hemos mencionado antes, de las tres últimas bendiciones que constituyen una sección de acción de gracias, sólo la XVIII es efectivamente una oración de este tipo. La bendición XVII, que comienza «Acepta, Yahvé nuestro Dios, la plegaria de tu pueblo Israel», y la XIX, que comienza «Otórganos paz, bienestar, bendición, gracia, piedad y misericordia a todo Israel» son en realidad, como reflejan las frases iniciales, oraciones peticionarias. Por otra parte, una categorización de las bendiciones en alabanzas, peticiones y acción de gracias puede resultar algo artificial por cuanto en ocasiones los límites entre estos tipos de bendiciones son difusos y a veces incluso se mezclan ${ }^{23}$.

Reuven Kimelman ${ }^{24}$ propone un análisis basado en una variante del método de la crítica literaria llamada crítica retórica. Según esta, la función retórica de la estructura literaria de un texto se basa en la persuasión, por lo que en el análisis concreto de la amidá se trata de ver las técnicas y recursos utilizados para que el destinatario del mensaje sea más receptivo a aquello de lo que se le quiere persuadir ${ }^{25}$. Para Kimelman, la amidá es una oración cuya función retórica es presentar un argumento convincente que dé esperanza para la redención de Israel. En ese sentido, la bendición I

20 Vid. Elbogen 1993, 25 [22]: «The 'Amida is divided into three sections: The first three benedictions form a hymnic introduction; the final three are a conclusion with thanksgiving; and the thirteen middle ones contain petitions». Este esquema es el que define Maimónides (Mišne Torah, Hilkot tefilah 1:4) y que se corresponde aproximadamente con el que definieron los rabinos del período amoraítico; así R. Hanina, quien compara las bendiciones con un esclavo ante su señor que primero le alaba, luego le pide, y finalmente se prepara para marchar (bBer. 34a), y R. Josué b. Levi, para quien las tríadas inicial y final son alabanzas que envuelven una sección intermedia con peticiones (yBer. 2:4, 4d).

21 Así Maimónides (Mišne Torah, Hilkot tefilah 1:4).

22 Por ejemplo, Kimelman 1997a y 1997b; Fleischer 1993. Kimelman (1997b, 175-199) ofrece una panorámica de las teorías de distintos autores, antiguos y modernos, sobre la estructura literaria de la amidá, y en particular sobre la ideología que se refleja en la estructura interna de la sección intermedia de bendiciones peticionarias.

23 Vid. Berkovits 1969, 127-128.

$241997 \mathrm{~b}$.

25 Kimelman huye, por tanto, de análisis literarios que estén relacionados con el desarrollo histórico del texto y su composición, y se centra en la amidá tal como aparece en la liturgia tradicional judía y como fruto literario de la época rabínica. 
presenta la idea del Dios redentor («traes la redención»), la bendición II promete la resurrección («Bendito seas, Yahvé, que resucitas a los muertos»), y la III proclama la santidad de Dios y su reino eterno sobre la tierra (este último concepto en la qedušah). Las bendiciones IV a IX presentan tres dimensiones en las que se produce la redención: en las bendiciones IV a VII, una dimensión personal de redención (por medio del conocimiento, el arrepentimiento, el perdón y la liberación) ${ }^{26}$; en la bendición VIII, una dimensión redentora de curación y salvación físicas; en la bendición IX, una dimensión redentora de fertilidad agrícola. Las bendiciones X a XV presentan un discurso de redención nacional: la reunión de los exiliados desde los confines de la tierra al toque del šofar (X); el imperio de la justicia y la rectitud (XI); la exterminación de los apóstatas (XII); la bendición de los justos (XIII); la reconstrucción de Jerusalén y el trono de David (XIV); y la reinstauración de la estirpe de David $(\mathrm{XV})$. La bendición XVI («recibe nuestra oración con misericordia») y la XVII («reinstaura el culto en el santuario de tu Templo») avanzan en la idea de redención que se convierte en la bendición XVIII en la exaltación de Yahvé y la aceptación universal de su reino («sea bendito y exaltado tu nombre, rey nuestro, eternamente»). La bendición XIX funciona a modo de conclusión con una petición por la paz sobre todo Israel. Así, la retórica de redención en la amidá se desarrolla desde la promesa personal, que se convierte en nacional y finalmente en universal, con una aceptación implícita de la soberanía de Dios.

Esta retórica de la redención en la amidá sólo puede entenderse, según Kimelman, como una pieza dentro del marco de la liturgia establecida en época rabínica, en la que el šema' y la amidá forman una unidad litúrgica que desarrollan la idea de la esperanza en la redención después del duro golpe de la destrucción del Templo y de la desaparición del sistema cúltico que en él se sustentaba: mientras que el šema se centra en el recuerdo de la redención acaecida en el pasado, la amidá presenta la promesa de redención futura ${ }^{27}$. Además de la promesa redentora, otros autores ven también en la estructura literaria de la amidá y de la liturgia rabínica en general elementos de cohesión comunal y de refuerzo de la identidad judía ${ }^{28}$.

El análisis literario de Kimelman nos ofrece una visión de lo que, en su opinión, es la retórica implícita en la liturgia rabínica establecida en el servicio religioso y basada en las dos oraciones básicas que lo constituyen, šema ' y amidá. No obstante, a las preguntas de cuándo, cómo y por qué surge la amidá, se han dado múltiples respuestas fruto de distintas aproximaciones metodológicas a las que nos vamos a acercar a continuación.

\section{Origen y desarrollo}

El origen y desarrollo temprano de la amidá ha sido uno de los temas más debatidos en el ámbito del estudio de la liturgia judía ${ }^{29}$, en conexión con el origen y estableci-

26 Vid. Kimelman 2008.

27 Kimelman 1997a, 117: «When the Amidah - with its theme of future redemption - was welded to the end of the liturgy of the Shema - with its theme of past redemption, the memory of past redemption provided the liturgical springboard for prayer concerning future redemption, creating a single integrated rabbinic liturgy».

28 Vid. Tabory 2003, 113; Langer 2003, 139.

29 La bibliografía sobre el tema es amplísima, por lo que aquí haremos referencia únicamente a los autores cuyas propuestas mencionaremos por ser fundamentales y a sus obras más destacadas. 
miento de una liturgia rabínica para la sinagoga basada en un orden de oraciones obligatorias, después de la destrucción del Templo de Jerusalén. Las fuentes rabínicas presentan un escenario en el que el concilio de rabinos en Yavne toma las decisiones fundamentales para sustituir el culto en el ya inexistente Templo, de carácter sacrificial, por un culto basado en un orden de oraciones recitadas por la comunidad en el ámbito de la sinagoga. Según estas mismas fuentes, la mayor parte de las oraciones eran preexistentes y habían sido compuestas en época muy antigua. En ese contexto, la labor de R. Gamaliel II fue encargar a Simeón ha-Paquli la reelaboración de la amidá ${ }^{30}$ y de institucionalizar su recitación obligatoria tres veces al día, así como de establecer el orden del resto de las oraciones en los diferentes servicios litúrgicos de los días ordinarios y de las fiestas.

Este panorama mítico fue puesto en evidencia a partir del s. XIX, con el inicio de los primeros estudios académicos sobre la liturgia judía. Las distintas aproximaciones metodológicas en el estudio de esta disciplina han sido descritas y convenientemente reseñadas por Richard Sarason ${ }^{31}$, por lo que aquí nos contentaremos con hacer una breve alusión a estas, haciendo mayor hincapié en las aportaciones surgidas del debate suscitado en los últimos veinticinco años acerca del origen de la liturgia judía en general, y de la amidá en particular.

Leopold Zunz, fundador del estudio moderno de la liturgia judía, aplicó el método histórico-filológico a los textos de las oraciones judías, asumiendo que cada oración había sido compuesta en un momento determinado por una persona en concreto $^{32}$. En el caso de la amidá, ese momento podía retrotraerse a la época del Segundo Templo o incluso al exilio en Babilonia, según los distintos argumentos. A pesar de la fijación e institucionalización del texto en el concilio de Yavne, la amidá habría sufrido cambios, añadidos y variantes, fruto del paso del tiempo y de la diversidad geográfica en que se han ubicado las distintas comunidades judías de la diáspora. El método histórico-filológico trata, pues, de separar lo central de lo accesorio y de dar con el texto original o arquetipo (Urtext). La evidencia de que en el caso de los textos litúrgicos judíos no se podía aplicar este método con el fin de hallar el arquetipo, puesto que este no habría existido nunca, fue puesta de manifiesto por Ismar Elbogen ${ }^{33}$, a pesar de que también aplicó con convicción el método histórico-filológico a estos textos. En su caso, sin embargo, este método le sirvió para distinguir los diferentes estratos cronológicos en la formación de las oraciones, dando por supuesto que no había un autor primigenio original y que la forma final era producto de la superposición de distintos materiales añadidos en varias etapas por personas distintas.

30 La tradición rabínica insiste en retrotraer la composición de los textos a un pasado remoto, justificando la acción de Simeón ha-Paquli como una organización de las bendiciones, puesto que esta se habría olvidado. El hecho de querer anclar la autoridad de los textos litúrgicos en un pasado remoto indica la voluntad de relacionar el culto sacrificial del Templo con la liturgia rabínica, así como la necesidad de justificar la actividad textual y legisladora de los rabinos en Yavne; vid. Langer 2003, 129: «While the rabbis wanted badly to retroject the origins of this liturgy into antiquity, neither they nor any of their contemporaries had any active experience of participating in this prayer prior to the establishment at Yavneh».

$31 \quad 1978$.

32 Vid. esp. Zunz 1892.

33 Elbogen 1993, 37-54 [33-47]. La edición original alemana (1913) fue traducida al hebreo por Joseph Heinemann en 1972. La traducción inglesa realizada por Raymond Scheindlin en 1993 contiene numerosas adiciones, comentarios y puesta al día del traductor, y tiene en cuenta tanto el texto original de 1913 como la traducción al hebreo de 1972. 
Un cambio metodológico radical llegaría con la aplicación del método de la crítica formal. Esta asume que no es posible encontrar fuentes o estratos documentales en unos textos cuyo componente básico es oral, popular y folklórico, y que por lo tanto no tiene sentido aplicar el método histórico-filológico. En lugar de buscar un arquetipo o fuentes documentales, se trata de analizar el texto en su contexto o 'situación vital' (Sitz im Leben), e identificar las unidades o formas literarias apropiadas para cada una de esas situaciones ${ }^{34}$. Joseph Heinemann aplicó este método al conjunto de la liturgia judía ${ }^{35}$, con unos resultados que han mantenido su vigencia prácticamente hasta la actualidad.

Según Heinemann, las oraciones litúrgicas no son textos literarios strictu senso, sino más bien literatura oral y folklórica, cuyo origen popular y múltiple generó una pluralidad textual inicial que sólo con el tiempo, y sobre todo debido a la acción reguladora y normalizadora de los rabinos, fue confluyendo en unos textos más o menos uniformes, aunque siempre con ligeras variantes. La transmisión textual medieval y la variedad de tradiciones litúrgicas surgidas durante la Edad Media habrían potenciado el desarrollo de algunas variantes, aunque conservando la uniformidad del texto conseguida por los rabinos durante los periodos tanaítico y amoraítico ${ }^{36}$. No hubo, por tanto, individuos concretos que decidieran componer tal o cual oración, sino un proceso popular, colectivo y orgánico de desarrollo de las oraciones ${ }^{37}$.

En el caso de la amidá, Heinemann encuentra la evidencia de este origen oral y folklórico, sujeto a un proceso de formación popular y colectivo, en los testimonios paralelos y otras fuentes ${ }^{38}$, tanto en los textos litúrgicos, como en la literatura de Qumran, Ben Sira (Eclesiástico) o la literatura judeo-helenística ${ }^{39}$. La existencia de series de bendiciones, letanías y oraciones en la época del Segundo Templo confirma, en su opinión, que la institucionalización de la amidá en Yavne no requirió la redacción de un texto nuevo, sino simplemente el recurso a series y bendiciones ya existentes que eran transmitidas de manera popular y colectiva ${ }^{40}$. Solo el esfuerzo de

34 Hermann Gunkel 1964 y 1986 fue el pionero en aplicar este método al estudio de la literatura de la Biblia hebrea, antes de que se utilizara en la liturgia judía. En el contexto litúrgico, Arthur Spanier (1939) ya cuestionó la validez del método histórico-filológico para el estudio de las oraciones judías, sugiriendo la aplicación sistemática de la crítica formal.

35 1977, con una versión anterior en hebreo.

36 El establecimiento canónico de las oraciones y de la liturgia quedó fundamentalmente fijado en el período gaónico, alrededor de los ss. IX y X, en Babilonia. Sobre la canonización de la liturgia judía, vid. Hoffman 1979. Testimonios del rito palestinense y otras variantes anteriores a esta época se han encontrado en los materiales de la Genizah de El Cairo; vid. p. ej. Schechter 1898; Wieder 1953.

37 En palabras de Heinemann 1977, 219: «The development of these prayers is not to be conceived as resulting from the studied actions of deliberative bodies which one day decided to "institute" certain benedictions or to "insert" an additional benediction, etc., but it is rather to be viewed as an organic process which sprang up among the people themselves, in their synagogues and houses of worship (as well as in the Temple, where certain prayers grew up around the sacrificial cult)».

38 Tabory (2003) analiza no los paralelos textuales, sino los elementos rituales cúlticos y litúrgicos que se celebraban en el Templo y que están descritos en las fuentes rabínicas. En su opinión, estos rituales son precursores de la institución de la amidá como punto central del culto a Yahvé en la liturgia rabínica.

39 Heinemann 1977, 219-220. Los paralelos entre algunas bendiciones de la amidá y el cántico de acción de gracias que incluye la versión hebrea de Eclo tras 51,12 parecen confirmar la idea de Heinemann de que existía un repertorio de bendiciones populares del que echaron mano los rabinos en Yavne para componer la amidá. Aunque la estructura y la formulación de este cántico y la amidá son distintas, los motivos mencionados coinciden en cinco ocasiones, que se encuentran en las bendiciones I, VII, X, XIV y XV (vid. notas a la traducción ad loc.).

40 Para Heinemann $(1977,224)$, lo que se hizo en Yavne fue «fixing the primary subject matter for each of the different benedictions, their arrangement in a particular order, as well as the determination of secondary subjects». 
los rabinos en época tanaítica y amoraítica conseguiría imponer una uniformidad en la amidá, nunca del todo conseguida, como reflejan las discusiones rabínicas, y que las tradiciones medievales conservarían añadiendo ciertas variantes en función del rito y de la comunidad.

Ezra Fleischer, en una serie de artículos dedicados al origen y desarrollo temprano de la liturgia judía ${ }^{41}$, y en particular al origen de la amidá, muestra su disconformidad total con la teoría de Heinemann y ofrece una serie de conclusiones basadas en el tratamiento metodológico de la literatura rabínica como fuente histórica fiable. En su opinión, los rabinos en Yavne establecieron un nuevo sistema cúltico basado en una liturgia de tipo verbal, que sustituiría al culto de tipo sacrificial que se practicaba en el Templo antes del año 70. La invención de un nuevo sistema como este no tiene sentido, argumenta Fleischer, si no se componen textos totalmente nuevos. La amidá, por tanto, sería uno de los principales textos de nuevo cuño compuestos en Yavne, y pasaría a ser, en este recién creado sistema litúrgico, de recitación obligatoria tres veces al día. De este modo toda la comunidad de Israel participaría en el culto de Yahvé independientemente de donde se encontrara ${ }^{42}$.

Los problemas de los argumentos de Fleischer han sido puestos de relieve en especial por Ruth Langer, quien mantuvo con este autor una serie de réplicas y contraréplicas sobre el método con que se deben analizar los textos de la literatura rabínica y sobre las conclusiones a las que él llega ${ }^{43}$. Pocos creen que el texto de la amidá fuera realmente compuesto de nuevo cuño en Yavne por Simeón ha-Paquli ${ }^{44}$, puesto que parece inverosímil que los rabinos crearan una oración fundamental como la amidá de la nada, y que fueran capaces de hacerla aprender y de imponer su recitación tres veces al día a todo el pueblo de Israel, en Palestina y en la diáspora, en tan corto período de tiempo, si no existieran precedentes tanto textuales como de liturgia verbal antes de la destrucción del Templo ${ }^{45}$.

Las afirmaciones de Fleischer son tanto más problemáticas por cuanto se fundamentan, por un lado, en su interpretación de los testimonios rabínicos, de dudosa validez histórica, y por otro, en el caso de la amidá, en el análisis del texto, un texto que desconocemos cómo podría haberse compuesto o reelaborado en Yavne, ya que el carácter oral de la liturgia en período rabínico evitó que las oraciones se pusieran por escrito. En efecto, no se conserva ningún libro de oraciones judío anterior al s. $\mathrm{IX}^{46}$ y los textos que nos han llegado son fruto de los procesos de redacción, transmisión y corrección acaecidos fundamentalmente a lo largo de la Edad Media y el s. XVI. No podemos asumir, por tanto, que el texto de la amidá sea tal cual el compuesto o reelaborado en Yavne, a pesar de que podamos pensar que los temas, el orden de las bendiciones y grandes porciones de texto existieran ya en esa época en un modo

$41 \quad$ Fleischer 1990; 1991; 1993; 1995.

42 Fleischer 1990, 433-435. Antes de la destrucción del Templo, no habría necesidad de una liturgia verbal puesto que toda la comunidad de Israel participaba en los sacrificios cúlticos por medio del pago anual de medio šeqel.

43 Reseña y discusión de los artículos mencionados de Fleischer en Langer 1999; réplica en Fleischer 2000; contra-réplica en Langer 2000. Tras este debate, en los últimos años no ha habido aportaciones significativas sobre el estudio de la liturgia rabínica temprana y el origen de la amidá. Vid. Langer 2017, 147.

44 Vid. Kimelman 1997a, 115: «The Amidah was not created ex nihilo. Comprised of elements some of which hark back to the Second Temple period, indeed to the Temple service itself, it crystallizes an extended process of liturgical composition». En línea con Heinemann y Petuchowski 1975, 31: «There is no reason to assume that the Amidah was originally composed and instituted by a central authority».

45 Sobre los precedentes de liturgia verbal antes de la destrucción del Templo, vid. Tabory 2003.

46 Vid. Langer 1999, 180. 
muy similar al que conocemos hoy. Tampoco es plausible creer que el nuevo sistema litúrgico ideado por lo rabinos fuera aceptado de un día para otro por toda la comunidad de Israel en Palestina y la diáspora, aprendiendo de inmediato oraciones de nuevo cuño compuestas para la ocasión ${ }^{47}$. Debemos, por tanto, admitir la posibilidad de que los rabinos aceptaran materiales existentes, series de oraciones y textos litúrgicos conocidos por el pueblo desde la época del Segundo Templo, y que los utilizaran, los reordenaran y acomodaran a una nueva realidad social y litúrgica, sin Templo y sin sacrificios cúlticos.

La labor de los rabinos en Yavne fue, en todo caso, revolucionaria, puesto que ellos y sus sucesores idearon un nuevo sistema ideológico basado en el estudio y en la liturgia verbal, y fueron capaces, no sin discusiones y opiniones enfrentadas, de convencer a gran parte de las comunidades judías de Palestina y de la diáspora de aceptar el nuevo sistema y una nueva ideología anclada en la tradición anterior pero remodelada y adaptada a la nueva realidad social. No hay que olvidar que la ideología rabínica debió de encontrar oposición en los primeros tiempos después de la destrucción del Templo, y que tuvo que luchar contra la cristianización de numerosas comunidades judías del Oriente Próximo. A pesar de una posterior idealización del tránsito de la época anterior a la destrucción del Templo y posterior, las propias fuentes rabínicas dejan entrever disputas y fuertes desacuerdos en el fondo de una lucha por el poder social y el control efectivo dentro del judaísmo ${ }^{48}$.

En este sentido, se entiende que la tradición rabínica se presente como sucesora de la tradición anterior y anclada en el pasado, y es asumible de igual modo que, en el ámbito litúrgico, más que imponer un sistema completamente nuevo con textos de nuevo cuño, prefiriera utilizar materiales, series de bendiciones y oraciones que fueran familiares, por lo menos en parte, para una mayoría de fieles.

\section{Apéndice: Una traducción anotada de la amidá}

La traducción que presentamos a continuación responde al texto de la amidá de diecinueve bendiciones, que se recita en los días ordinarios no festivos, según el texto normativo aceptado en las tradiciones sefardí y askenazí. ${ }^{49}$ El texto es básicamente el mismo en ambas tradiciones, aunque con algunas pequeñas diferencias que se indican convenientemente. Se indican, asimismo, las adiciones propias de las estaciones, de los días de ayuno público, de los diez días de arrepentimiento (yamim nora 'im) que hay entre Año Nuevo y el Día de la Expiación, así como otras adiciones en fiestas específicas. Tras la amidá de diecinueve bendiciones, presentamos la traducción de la santificación del día (qedušat ha-yom) en la bendición intermedia de la amidá del sábado y las fiestas.

$47 \quad$ En palabras de Langer 1999, 190: «Fleischer assumes that Rabban Gamliel could decree that everyone must pray a new complex set of prayers three times a day, and people simply rearranged their lives to accommodate this. The Rabbis, in their own literature, naturally portray themselves as immediately taking care of the Jewish world after the fall of the Temple and establishing laws and customs that everyone obeyed more or less without fuss. But is it reasonable to accept this as history?»

48 Vid. Langer 1999, 190.

49 El texto base para esta traducción se encuentra en Siddur Tefillas Shlomo Hashalem. Nusach Sefarad, 2007, Brooklyn, New York. 
[Sección inicial $\left.{ }^{50}\right]$

I. (Padres)

Bendito seas, Yahvé, dios nuestro, dios de nuestros padres, dios de Abraham, dios de Isaac y dios de Jacob, gran dios, poderoso, temible, dios altísimo, piadoso, que todo lo posees, que te acuerdas de los buenos actos de [nuestros] padres y traes la redención a sus hijos ${ }^{51}$, por amor de su [tu] nombre ${ }^{52}$. Eres rey que ayuda, salva y protege. Bendito seas, Yahvé, escudo ${ }^{53}$ de Abraham.

\section{II. (Poderes)}

Eres eternamente poderoso, Señor, [solo] tú resucitas a los muertos y eres quien da la salvación. ([En verano:] Haces caer el rocío ${ }^{54}$; [en invierno:] levantas el viento y traes la lluvia]), sustentas al vivo piadosamente, resucitas a los muertos con misericordia, sostienes al que cae, curas al enfermo, liberas al cautivo, y mantienes tu promesa [de resurrección] con el que está enterrado ${ }^{55}$. ¿Quién hay como tú, que posees tanto poder? ¿Quién hay que se te parezca? Eres rey que das la muerte y la vida, [solo en ti] está la salvación ${ }^{56}$, y permaneces fiel [en tu promesa] de resucitar a los muertos. Bendito seas, Yahvé, que resucitas a los muertos.

\section{$\left(\left[Q e d u \check{s} a h^{57}:\right]\right.$}

[Introducción en el rito sefardí:] Te santificamos y te reverenciamos, lo mismo que deliciosamente lo hacen los santos serafines en su lenguaje secreto, que recitan tres veces tu santificación, según está escrito por medio de tu profeta:

[Introducción en el rito askenazí:] Santificamos tu nombre en el mundo, lo mismo que se lo santifica en los elevados cielos, según está escrito por medio de tu profeta:

Se dijeron uno a otro, clamando de este modo:

Santo, Santo, Santo es Yahvé SSeba'ot, su gloria llena toda la tierra.

[En el rito sefardí:] Frente a ellos, [otros] lo alababan y decían:

[En el rito askenazí:] Frente a ellos, [otros] lo llamaban «Bendito»:

Bendita sea la gloria de Yahvé, desde su morada.

Y en tus santas palabras está escrito:

Yahvé reina eternamente, tu Dios, ¡oh, Sión!, de generación en generación, aleluya.)

$50 \quad$ Antes de empezar, se recita Sal 51,17.

51 Literalmente, «a los hijos de sus hijos», es decir, a sus descendientes.

52 En los diez días de arrepentimiento entre Año Nuevo y el Día de la Expiación se recita también: «Acuérdate de nosotros para la vida, rey que amas la vida, y anótanos en el libro de la vida, porque tú eres Dios vivo».

53 Cfr. Eclo 51,12 (hebreo): «Dad gracias al escudo de Abraham, porque su misericordia es eterna» (trad. Sagrada Biblia 1979, ad loc.).

54 La tradición askenazí no recita este atributo de verano.

55 Literalmente, «con los que duermen [bajo] el polvo».

56 Literalmente, «tú haces florecer la salvación». En los diez días de arrepentimiento entre Año Nuevo y el Día de la Expiación se recita también: «¿Quién hay como tú, tan misericordioso, que se acuerde de sus criaturas para la vida con [tanta] misericordia?»

57 Sin la conclusión que en el rito askenazí recita el oficiante en la repetición de la amidá. 


\section{III. (Santificación)}

Eres santo, y santo es tu nombre, y los santos te alaban cada día, selah. Bendito seas, Yahvé, dios santo ${ }^{58}$.

[Sección intermedia]

IV. (Sabiduría)

Otorgas conocimiento al hombre, y enseñas sabiduría al ser humano. ¡Otórganos discernimiento, sabiduría e inteligencia! Bendito seas, Yahvé, que otorgas conocimiento.

\section{V. (Arrepentimiento)}

Haznos volver, padre nuestro, a tu ley, aproxímanos, rey nuestro, a tu culto, y llévanos ante ti con profundo arrepentimiento ${ }^{59}$. Bendito seas, Yahvé, que deseas [nuestro] arrepentimiento.

\section{VI. (Perdón)}

Perdónanos, padre nuestro, porque hemos pecado, discúlpanos, rey nuestro, por haber cometido falta, ([en el rito sefardí:] pues eres un dios bueno e indulgente; [en el rito askenazí:] pues tú disculpas y perdonas]). Bendito seas, Yahvé, que eres piadoso y dispuesto al perdón ${ }^{60}$.

\section{VII. (Liberación)}

Mira nuestra pobreza, lucha por nuestra causa, y libéranos pronto por causa de tu nombre, pues eres un potente redentor. Bendito seas, Yahvé, que liberas a Israel $^{61}$.

\section{VIII. (Curación)}

Cúranos, Yahvé, y nos curaremos, sálvanos, y nos salvaremos, pues tú eres nuestra gloria. Cura por completo todas nuestras heridas, porque tú eres dios rey que permaneces fiel y misericordioso [en tu promesa de] curación ${ }^{62}$. Bendito seas, Yahvé, que curas al enfermo de entre su [tu] pueblo Israel.

58 En los diez días de arrepentimiento entre Año Nuevo y el Día de la Expiación se dice: «rey santo».

59 El término tešubah, aquí traducido como 'arrepentimiento', implica contrición, arrepentimiento y deseo de perdón o vuelta a la gracia de Dios. Así, en «llévanos ante ti con profundo arrepentimiento» va implícita la idea de volver a la gracia de Dios después de un sincero arrepentimiento por no haber cumplido su ley.

60 Literalmente, «multiplicas el acto de perdonar».

${ }^{61}$ Cfr. Eclo 51,12 (hebreo): «Dad gracias al redentor de Israel, porque su misericordia es eterna» (trad. Sagrada Biblia 1979, ad loc.) En los días de ayuno público, tras esta bendición, el oficiante recita en la repetición de la amidá una oración llamada Anenu. Vid. mTa 'an. 2:4.

62 Literalmente, «curador fiel y misericordioso», es decir, en quien se puede confiar plenamente que va a curar, porque es misericordioso. 
IX. $\left(\right.$ Años $\left.{ }^{63}\right)$

Bendice y favorece, Yahvé dios nuestro, este año y sus cosechas ${ }^{64}$, ([en verano:] y otorga [tu] bendición; [en invierno:] y concede el rocío y la lluvia como bendición) sobre la faz de la tierra. Sácianos de tus favores, y bendice [este] año nuestro como los mejores años. Bendito seas, Yahvé, tú que bendices los años.

\section{X. (Reunión de los exiliados)}

Haz sonar el gran šofar [cuando] nuestra liberación, iza el estandarte [cuando] nuestra vuelta del destierro, y reúnenos desde los confines de la tierra ${ }^{65}$. Bendito seas, Yahvé, que reúnes a los exiliados de su [tu] pueblo Israel ${ }^{66}$.

XI. (Juicio [final])

Haz que volvamos a tener jueces, como antes, y líderes ${ }^{67}$, como al principio. Aparta de nosotros el dolor y la tristeza, reina sólo tú, Yahvé, sobre nosotros, con piedad y misericordia, y haznos justicia en el juicio [final]. Bendito seas, Yahvé, rey que amas la rectitud y la justicia ${ }^{68}$.

XII. (Apóstatas ${ }^{69}$ )

Que los calumniadores no tengan ninguna esperanza, que cualquier maldad desaparezca en un momento, que todos tus enemigos sean exterminados en seguida, y extirpa de raíz a los apóstatas, destrózalos, aniquílalos y somételos rápidamente en nuestros días. Bendito seas, Yahvé, que destrozas a los enemigos y sometes a los apóstatas.

XIII. (Justos)

Por los justos, por los piadosos, por los ancianos de tu pueblo, de la estirpe de Israel, por lo que ha quedado de sus escribas ${ }^{70}$, por los convertidos honestamente, y por nosotros: que se conmueva tu misericordia, Yahvé dios nuestro, concede una buena recompensa a los que se confían a tu nombre con verdad, haznos partícipes de su destino ${ }^{71}$, y que no seamos objeto de humillación por confiarnos a ti. Bendito seas, Yahvé, que eres sostén y apoyo de los justos.

63 Se refiere al año como unidad del ciclo agrícola.

64 Literalmente, «Bendice para nosotros, Yahvé dios nuestro, este año y todas sus clases de grano para bien».

65 Literalmente, «desde las cuatro alas de la tierra».

${ }^{66} C f r$. Eclo 51,12 (hebreo): «Dad gracias al que reúne a los dispersos de Israel, porque su misericordia es eterna» (trad. Sagrada Biblia 1979, ad loc.)

67 Literalmente, «nuestros consejeros». Esta petición responde a la promesa de Isa 1,26.

68 En los diez días de arrepentimiento entre Año Nuevo y el Día de la Expiación se dice: «rey del juicio [final]».

69 No está claro si los apóstatas a los que hace referencia esta bendición son los cristianos, algún otro grupo heterodoxo judío, enemigos políticos fuera del judaísmo, como los romanos, o simplemente los malvados en general. Vid. Langer 2003,141-143; Stemberger 2011 (2009), 200; sobre esta bendición, vid. esp. Ehrlich 2005; Marcus, 2009; van der Horst 1994; Kimelman 1981.

70 Como transmisores de la Ley.

71 Literalmente, «pon nuestra parte con ellos para siempre». 
XIV. (Jerusalén)

A Jerusalén, tu ciudad, regresa con misericordia, habita en ella según prometiste, reconstrúyela definitivamente y para siempre ${ }^{72}$ pronto en nuestros días, y dispón ya el trono de David. Bendito seas, Yahvé, que reconstruyes Jerusalén ${ }^{73}$.

XV. (David)

Haz florecer pronto la semilla de David ${ }^{74}$, tu siervo, exáltala con tu salvación [hacia nosotros], pues todos los días ansiamos tu salvación. Bendito seas, Yahvé, que suscitas un atisbo de salvación ${ }^{75}$.

XVI. (Oración)

Escúchanos, Yahvé dios nuestro, compadécenos, ten piedad de nosotros, recibe nuestra oración con misericordia y [buena] voluntad, puesto que eres dios que escucha oraciones y ruegos. No nos dejes de vacío ${ }^{76}$, rey nuestro, pues tú escuchas la oración de tu pueblo Israel con misericordia. Bendito seas, Yahvé, que escuchas [esta] oración.

[Sección final]

XVII. (Culto)

Acepta, Yahvé dios nuestro, la plegaria de tu pueblo Israel, reinstaura el culto en el santuario de tu templo, recibe de buena voluntad la oración de la comunidad de Israel $^{77}$, y que sea tu voluntad aceptar siempre el culto de Israel, tu pueblo ${ }^{78}$.

XVIII. (Acción de gracias)

Te damos gracias por ser tú Yahvé nuestro dios y el dios de nuestros padres, eternamente. Roca de nuestra vida y nuestro escudo de salvación eres tú generación tras generación. Te damos gracias y cantamos tus alabanzas, porque nuestras vidas están en tus manos, porque nuestras almas están confiadas a ti, y por los milagros, prodigios y favores con que nos prodigas en todo momento, mañana tarde y noche ${ }^{79}$. Eres

\footnotetext{
Literalmente, «constrúyela como construcción eterna».

Cfr. Eclo 51,12 (hebreo): «Dad gracias al que reconstruye su ciudad y su templo, porque su misericordia es eterna» (trad. Sagrada Biblia 1979, ad loc.).

74 Cfr. Eclo 51,12 (hebreo): «Dad gracias al que hizo florecer el cuerno en la casa de David, porque su misericordia es eterna» (trad. Sagrada Biblia 1979, ad loc.).

75 Literalmente, «que haces florecer un rayo de salvación».

76 Literalmente, «de ante ti, rey nuestro, no nos hagas volver de vacío».

77 Literalmente, «los hombres de Israel, y su oración, recibe con amor y voluntad».

78 En el primero de mes o luna nueva (roš hodeš), en los festivales de peregrinación (excepto en el servicio adicional), y en el servicio ne 'ilah del Día de la Expiación, se recita, tras esta bendición, una oración llamada ya 'ale ve-yabo', que los sefardíes recitan además en el servicio adicional de Año Nuevo y del Día de la Expiación.

79 Literalmente, «por tus milagros que cada día [hay] con nosotros, y por tus prodigios y favores en todo momento, tarde, mañana y mediodía».
} 
bondadoso y compasivo, pues tu misericordia no tiene fin, ni tiene término tu piedad. Desde siempre ponemos nuestras esperanzas en $\mathrm{ti}^{80}$.

Por todo esto, sea bendito y exaltado tu nombre, rey nuestro, eternamente ${ }^{81}$.

Que todo ser vivo te dé gracias, selah, y alabe tu nombre sinceramente, dios, [que eres] nuestra salvación y nuestro auxilio, selah. Bendito seas, Yahvé, tú [que eres] de nombre bondadoso y a quien alabamos gozosamente ${ }^{82}$.

\section{([Bendición sacerdotal:]}

Dios nuestro y Dios de nuestros padres, bendícenos con la triple bendición que está en la ley, escrita por Moisés tu siervo, pronunciada por Aarón y sus hijos, los sacerdotes de tu pueblo santo, de esta manera:

Que Yahvé te bendiga y guarde; [la congregación responde:] así sea su voluntad.

Que Yahvé te ilumine con la luz de su rostro y te conceda su gracia; [la congregación responde:] así sea su voluntad.

Que Yahvé alce su rostro hacia ti y te conceda la paz; [la congregación responde:] así sea su voluntad.)

XIX. $(\mathrm{Paz})^{83}$

Otórganos paz, bienestar, bendición, gracia, piedad y misericordia a todo Israel, tu pueblo. Bendícenos, padre nuestro, a todos nosotros como a uno solo con la luz de tu rostro, puesto que nos has concedido [contemplar] la luz de tu rostro, Yahvé nuestro dios, [tú que eres] ley viva, amor piadoso, justicia, bendición, misericordia, vida y paz. Que te sea grato bendecir con la paz a tu pueblo Israel en todo momento y ocasión $^{84}$.

Bendito seas, Yahvé, que bendices a tu pueblo Israel con la paz ${ }^{85}$.

[Sección intermedia de la amidá del sábado]

Incluimos aquí únicamente la santificación del día, que es la parte fundamental y más antigua en la sección intermedia de la amidá del sábado y las fiestas. Esta sección va introducida por una serie de plegarias que son distintas en cada uno de los

80 Mientras el oficiante repite esta bendición, la congregación recita una oración llamada modim de-rabbanan. En las fiestas de Hanukah y Purim, se añaden, tras esta oración, sendas secciones conmemorativas de los acontecimientos celebrados en esas fiestas, la dedicación del Templo y la salvación de los judíos de Persia, respectivamente.

81 En los diez días de arrepentimiento entre Año Nuevo y el Día de la Expiación se añade: «e inscribe [en el libro de la vida] para una vida venturosa a los que mantienen tu pacto».

82 Literalmente, «el bien es tu nombre y a ti es gozoso alabar».

83 En el rito askenazí se recita esta bendición en el servicio matutino, y se sustituye por otra, denominada Šalom $r a b$, en los servicios vespertino y nocturno.

${ }_{84}$ En los diez días de arrepentimiento entre Año Nuevo y el Día de la Expiación se añade: «Que seamos recordados e inscritos en el libro de la vida, [con] bendición, paz, sustento y bondad, nosotros y todo tu pueblo, de la estirpe de Israel, para una vida venturosa y pacífica».

85 Tras esta última bendición, se recita Sal 19,15. En la recitación personal y silenciosa, se añade, además, la oración llamada de Mar ben Rabina. Ésta es seguida, en el rito sefardí, por una plegaria adicional que comienza «Sea tu voluntad, Yahvé Dios nuestro y Dios de mis padres, que no caiga sobre mí la envidia de los otros». Se concluye con una oración que comienza «Hazlo por [amor a] tu nombre», a la que se suele añadir la plegaria «Sea tu voluntad, Yahvé Dios nuestro y Dios de nuestros padres, que se reconstruya el Templo». 
servicios del sábado, y que fueron introducidas a lo largo del período saboraítico y gaónico.

\section{IV. (Santificación del día)}

Dios nuestro y dios de nuestros padres, sea tu voluntad que [hoy] descansemos, bendícenos con tus mandamientos, haznos partícipes de tu Ley, sácianos de tu bondad, ([en el rito sefardí:] alegra nuestra alma; [en el rito askenazí:] alégranos) con tu salvación, purifica nuestros corazones para rendirte culto sincero, y otórganos, Yahvé dios nuestro, tu sábado santo con amor y voluntad, de manera que en [este día] descanse Israel, que santifica tu nombre. Bendito seas, Yahvé, que santificas el sábado.

\section{Bibliografía}

Berkovits, E., 1969, “Prayer”, en L. Stitskin (ed.), Studies in Torah Judaism, New York, 81-189. Brody, R., 2006, "Liturgical Uses of the Book of Psalms in the Geonic Period" en J. Kugel, Prayers that Cite Scripture, Cambridge, Mass., 61-81.

Elbogen, I., 1993, Jewish Liturgy: A Comprehensive History, (trad. ingl. por Raymond P. Scheindlin, basado en el original alemán de 1913 y en la trad. hebrea de Joseph Heinemann et al. de 1972), Philadelphia - New York - Jerusalem.

Ehrlich U.; Langer, R. 2005, "The earliest texts of the Birkat Haminim", Hebrew Union College Annual 77, 63-112.

Fleischer, E., 1990, “On the Beginnings of Obligatory Jewish Prayer", Tarbiz 59, 397-441. [hebreo]

Fleischer, E., 1991, "Annual and Triennal Reading of the Bible in the Old Synagogue", Tarbiz 61, 25-43. [hebreo]

Fleischer, E., 1993, "The Shemoneh 'Esreh. Its Character, Internal Order, Content and Goals", Tarbiz 62, 179-223. [hebreo]

Fleischer, E., 1995, "On the Early Formulation of the Fourth Benediction of the Sabbath Amidah", Bar Ilan Annual 26-27, 249-258. [hebreo]

Fleischer, E., 2000, "On the Origins of the "Amidah. Response to Ruth Langer", Prooftexts 20/3, 380-384.

Gunkel, H., 1964, The Legends of Genesis: the Biblical Saga and History, (trad. alem. por W. H. Carruth), New York.

Gunkel, H., 1986, Die Psalmen, Göttingen.

Heinemann, J., 1977, Prayer in the Talmud: Forms and Patterns, Berlin - New York.

Heinemann, J.; Petuchowski, J. (eds.), 1975, Literature of the Synagogue, New York.

Hoffman, L., 1979, The Canonization of the Synagogue Service, Notre Dame, Ind.

Horst, P. W. van der, 1994, "The Birkat ha-Minim in Recent Research" en P. W. van der Horst (ed.), Hellenism - Judaism - Christianity: Essays on Their Interaction, Kampen, 99-111.

Kahana, M., 2007, “The Arrangement of the Orders of the Mishnah", Tarbiz 76, 29-40. [hebreo] Kimelman, R., 1981, "Birkat ha-Minim and the Lack of Evidence for an Anti-Christian Jewish Prayer in Late Antiquity" en E. P. Sanders et al. (eds.), Jewish and Christian Self Definition, vol. II: Aspects of Judaism in the Graeco-Roman Period, Philadelphia, 226-244.

Kimelman, R., 1997a, “The Shema and the Amidah: Rabbinic Prayer" en M. Kiley et al. (intr. y ed.), Prayer from Alexander to Constantine: A critical anthology, London - New York, 108-120. 
Kimelman, R., 1997b, “The Literary Structure of the Amidah and the Rhetoric of Redemption” en W. G. Dever y J. E. Wright, (eds.), The Echoes of Many Texts: Reflections on Jewish and Christian Traditions. Essays in Honor of Lou H. Silberman, Atlanta, 171-218. Kimelman, R., 2008, "The Penitential Part of the Amidah and Personal Redemption", en M. J. Boda et al. (eds.), Seeking the Favor of God, vol. 3: The Impact of Penitential Prayer beyond Second Temple Judaism, Atlanta, Ga., 71-84.

Kugel, J., 2006, Prayers that Cite Scripture, Cambridge, Mass.

Langer, R., 1999, "Revisiting Early Rabbinic Liturgy: The Recent Contributions of Ezra Fleischer", Prooftexts 19/2, 179-204.

Langer, R., 2000, "Considerations of Method. A Response to Ezra Fleischer", Prooftexts 20/3, 384-387.

Langer, R., 2003, “The 'Amidah as Formative Rabbinic Prayer”, en A. Gerhards et al. (eds.), Identität durch Gebet: Zur gemeinschaftsbilderen Funktion institutionalisierten Betens in Judentum und Christentum, Paderborn - München - Wien - Zürich, 127-156.

Langer, R., 2007, "Biblical Texts in Jewish Prayers: Their History and Function" en A. Gerhards y C. Leonhard (eds.), Jewish and Christian Liturgy and Worship: New Insights into its History and Interaction, Leiden - Boston, 63-90.

Langer, R., 2017, "New Directions in Understanding Jewish Liturgy" en F. E. Greenspahn (ed.), Early Judaism: New Insights and Scholarship, Nueva York, 147-173.

Marcus, J., 2009, “Birkat ha-minim revisited”, New Testament Studies 55/4, 523-551.

Naeh, Sh., 2006, "The Role of Biblical Verses in Prayer According to the Rabbinic Tradition" en J. Kugel, Prayers that Cite Scripture, Cambridge, Mass., 43-59.

Petuchowski, J. (ed.), 1970, Contributions to the Scientific Study of Jewish Liturgy, New York.

Reif, S., 2006, Problems with Prayers: Studies in the Textual History of Early Rabbinic Liturgy, Berlin - New York.

Sagrada Biblia, $1979^{2}$ (trad. esp. por F. Cantera Burgos y M. Iglesias González). Versión crítica sobre los textos hebreo, arameo y griego, Madrid.

Sarason, R., 1978, "On the Use of Method in the Modern Study of Jewish Liturgy" en W. S. Green (ed.), Approaches to Ancient Judaism: Theory and Practice, Missoula, Mt., $97-$ 172.

Schechter, S., 1898, “Geniza Specimens”, Jewish Quarterly Review o.s. 10, 655-659 (re. en J. Petuchowski [ed.], Contributions to the Scientific Study of Jewish Liturgy, New York, 1970).

Schürer, E., 1985, Historia del pueblo judio en tiempos de Jesús, 175 a.C.-135 d.C., 2 vols., (trad. J. Cosgaya, A. Piñero y J. Valiente Malla), Madrid (The History of the Jewish People in the Age of Jesus Christ, 2 vols., Edimburg, 1979).

Siddur Tefillas Shlomo Hashalem. Nusach Sefarad, 2007, New York.

Spanier, A., 1939, "Dubletten in Gebetstexten", Monatsschrift für Geschichte und Wissenschaft des Judentums LXXXIII, 142-149.

Stemberger, G., 2011, El judaísmo clásico: Cultura e historia del período rabínico (trad. Lorena Miralles Maciá), Madrid (Das klassische Judentum: Kultur und Geschichte der rabbinischen Zeit, München, 2009).

Tabory, J., 2003, "The Precursors of the "Amidah" en A. Gerhards. et al. (eds.), Identität durch Gebet: Zur gemeinschaftsbilderen Funktion institutionalisierten Betens in Judentum und Christentum, Paderborn - München - Wien - Zürich, 113-125.

Weinfeld, M., 2005, Normative and Sectarian Judaism in the Second Temple Period, London. 
Wieder, N., 1953, “The Old Palestinian Ritual - New Sources”, Journal of Jewish Studies 4, 33-37.

Zunz, L., 1892², Die gottesdienstlichen Vorträge der Juden: historisch entwickelt, Frankfurt: J. Kauffmann (re. Piscataway, N.J., 2003). 